\title{
Inflammation in pulmonary arterial hypertension: is it time to quell the fire?
}

\author{
Paul M. Hassoun \\ Affiliations: Division of Pulmonary and Critical Care Medicine, Dept of Medicine, Johns Hopkins University,
} School of Medicine, Baltimore, MD, USA.

Correspondence: P.M. Hassoun, Division of Pulmonary and Critical Care Medicine, 1830 East Monument Street, Baltimore, MD 21287, USA. E-mail: phassoundjhmi.edu

Two new studies demonstrate an association between circulating inflammatory mediators and mortality in PAH http://ow.ly/szrQo

Inflammare, or to set ablaze, is the Latin origin of the word inflammation, a physical condition that was undoubtedly already familiar to the ancient Egyptians and Greeks. It is, however, the Roman Aulus Celsus who is credited with describing, in the first century $\mathrm{AD}$, the four cardinal signs of inflammation consisting of rubor et tumor cum calore et dolore (redness and swelling with heat and pain). Two centuries later, Galen promoted the humoral view of inflammation as a potential part of the healing process rather than a pure pathological process, and may have proposed the fifth cardinal sign (functio laesa or loss of function) [1], although this is also attributed to Virchow in the 19th century [2]. And while we now know that, in many pathologies characterised by inflammation, the initial four cardinal signs can be subclinical and silent, it is clear that for Virchow inflammation was ultimately pathologic since it lead to loss of function.

What is then going on in pulmonary arterial hypertension (PAH)? Over the past 120 years since the first pathologic description of "pulmonary vascular sclerosis" by Romberg, our understanding of the remodelling process underlying what we now call $\mathrm{PAH}$ has greatly changed from a mere description of the thickening of the three components of the pulmonary vascular wall leading to narrowing of the lumen, to aberrant cellular proliferation (e.g. endothelial and smooth muscle cells and fibroblasts) and influx of inflammatory cells in and around the various components of the vascular wall. TUDER et al. [3] were among the first to describe a significant influx of inflammatory cells, including macrophages and lymphocytes, into the plexiform lesions of hypertensive pulmonary vessels. Within a few years, other markers of inflammation, including macrophage inflammatory protein- $1 \alpha$, interleukin (IL)-1 $\beta$ and IL-6 [4, 5], and P-selectin [6], as well as mediators of the lipoxygenase pathway (e.g. 5-lipoxygenase and 5-lipoxygenase activating protein or FLAP) $[7,8]$ were found to be highly expressed in severe idiopathic PAH in human disease, as well as in animal models. The association between inflammation and vascular remodelling was further strengthened by the observation of circulating antibodies [9] (e.g. antibodies to endothelial cells [10, 11] and fibroblasts [12]) in PAH and association of this syndrome with certain autoimmune (e.g. connective tissue diseases [13] and thyroiditis) and infectious (e.g. HIV) [14] diseases. In fact there has been over the past few decades an exponential rise of articles in the literature dealing with the role of inflammation in PAH [15]. As PAH specialised centres have started collecting sera from patients in a prospective fashion, an explosion of inflammatory markers have been identified in association with PAH, including cytokines [16, 17], cytokinelike hormones [18], and angiogenic modulatory proteins with potential inflammatory properties (e.g. soluble endoglin and vascular endothelial growth factor receptor-1) [19] to cite a few examples.

Received: Jan 082014 | Accepted after revision: Jan 102014

Support statement: Supported by NIH/NHLBI HL114910 and P50 HL084946.

Conflict of interest: Disclosures can be found alongside the online version of this article at www.erj.ersjournals.com 
While observing an association between markers of inflammation and $\mathrm{PAH}$ is an important first stage, proving a causal (e.g. functio laesa) or potentially protective effect is the next step, while therapeutically targeting an inflammatory pathway of interest is the logical ultimate goal. In the meantime, a broad approach of measuring several circulating inflammatory cytokines and further demonstrating a link between altered expression and survival has recently proved effective. As a case in point, pioneering work from Soon et al. [20] demonstrated significantly increased levels of a broad range of cytokines (essentially tumour necrosis factor (TNF)- $\alpha$, interferon- $\gamma$, and interleukins $1,2,4,6,8$ and 10) in a relatively small group of patients with idiopathic and heritable PAH compared to control subjects. Furthermore, these investigators demonstrated decreased survival in patients with elevated levels of IL-6 [20]. In this issue of the European Respiratory Journal, letters from two groups of investigators reflect some further progress in this direction.

The first letter by CRACOWSKI et al. [21] from the French Network of Pulmonary Hypertension used a multicentre prospective cohort study of idiopathic, heritable and drug or toxin-induced PAH patients followed during a period of 3 years and for whom a biobank of plasma was stored. Using a multivariable Cox proportional hazards model, the authors demonstrated that increased levels of various cytokines (such as IL- $1 \alpha$, IL-1 $\beta$, TNF- $\alpha$ and IL-13, measured by a highly sensitive multiplex assay) independently predicted higher mortality. Surprisingly, however, increased IL-6, which had previously been shown to be a predictor of mortality by Soon et al. [20], was only associated with a nonsignificant trend towards increased likelihood of death. Despite the acknowledged limitations of this study (including the fact that the cohort is small; that the cohort is, unusually, predominantly male, although without a convincing explanation for this oddity; and the possibility of cytokine instability, as the assays were run at a time remote from sampling, which might explain differences in levels compared to other studies [20]), one of the predominant strengths of this study is undoubtedly the fact that it focused entirely on incident (i.e. newly diagnosed) cases of PAH, hence patients who were not already on therapy (which could have potentially affected levels). This is important considering known differences in survival between incident and prevalent PAH populations [22]. The authors wisely caution against drawing premature conclusions regarding the exact role of these cytokines in the pathogenesis of PAH disease. In fact, recent pre-clinical data demonstrate both a protective [23] and deleterious [24] role in the pathogenesis of experimental pulmonary hypertension, at least in the case of IL-6.

In a second letter published in the current issue, Heresi et al. [25] from the Cleveland Clinic, also using a prospective biobank obtained from patients with group 1 disease (heritable and idiopathic PAH, connective tissue- and congenital heart disease-associated $\mathrm{PAH}$ ), sought to demonstrate using Cox models an association between a cytokine (circulating IL-6), the acute phase C-reactive protein (CRP, a marker of cardiovascular risk regulated by IL-6) and mortality. Like the study by CRACOWSKI et al. [21], the patient sample size is relatively modest (76 patients), although in this case the sex ratio (female/male $81 \%$ ) is more consistent with that expected for PAH. Unlike the study by CRACOWSKI et al. [21], in which there is almost strict homogeneity, this is more of a mixed population from group 1 disease in the Cleveland study, and a vast majority of patients are already on therapy at the time of blood drawing. Using ROC curve analysis, the investigators demonstrate that IL-6 had better discrimant ability to predict mortality compared to CRP. Using a multivariable Cox model, male sex, brain natriuretic peptide (BNP) (both known predictors of mortality in PAH), and IL-6 were independently associated with mortality. Furthermore, using recursive partitioning tree-based analysis to identify a group of biomarkers and baseline clinical variables with the best discriminatory ability to predict mortality, the authors observed that the combination of baseline 6-min walk distance and right atrial pressure (known predictors of mortality in PAH) combined with IL-6 with a cut-off of $5.6 \mathrm{pg} \cdot \mathrm{mL}^{-1}$ had the optimal ability to separate survivors from nonsurvivors irrelevant of BNP levels. A major limitation of this partitioning strategy, however, is the very small number of patients in each of the three groups analysed, particularly the one at most risk (i.e. patients with elevated right atrial pressure and IL-6 and whose 6-min walk distance was decreased). An interesting twist in this study is the analysis combining several biomarkers/clinical variables, knowing that in PAH there is at the present time no "holy grail" for a best predictor of survival. Limitations include several of the same concerns raised regarding the French study, including the relatively modest number of patients, the problem of cytokine stability (as plasma was stored), and the lack of validation of the findings in an independent cohort.

So where do we stand in our knowledge of inflammation in PAH and where should we head from here? Is inflammation part of the healing process, as suggested by Galen, or on the contrary responsible for functio laesa which, in the case of $\mathrm{PAH}$, would be the inability of the pulmonary vasculature to provide adequate gas exchange and progressive remodelling ultimately resulting in right ventricular failure and death? These two letters certainly confirm previous work of an association of increased cytokines and mortality in PAH. Along with previous similar reports and recent pathological descriptions highlighting the degree of inflammation and lymphoid neogenesis in the vascular remodelling process $[26,27]$, these observations 
point a clear accusatory finger at the role of inflammation in the ultimate loss of function in PAH, death. Is it then time to quell the fire at an early stage in PAH before it is set out of control?

At this time, there is certainly no evidence that immunosuppression is effective, except perhaps in isolated cases of PAH related to certain connective tissue diseases, such as lupus and mixed connective tissue disease [28]. Of the current armamentarium of PAH drugs, none specifically targets inflammation. There is an ongoing double-blind, placebo-controlled, multicentre, randomised trial evaluating the effect of rituximab (a monoclonal antibody targeted against the CD20 antigen and resulting in B-cell depletion) on disease progression in subjects with scleroderma-associated PAH on stable PAH therapy [29]; however, the results will not be known for some time. Tyrosine kinase inhibitors which held some promise as anti-growth and anti-inflammatory drugs are clearly not ready for prime time in PAH [30].

In closing comments, as one ponders about the role of inflammation in $\mathrm{PAH}$, it is quite peculiar that the recent findings of exuberant inflammation and lymphoid neogenesis in remodelled vessels [26, 27] escaped the meticulous scrutiny of veteran pathologists such as WAGENVOoRT [31] and PIETRA et al. [32] over the years. Could it be that inflammation is a late response in this disease as survival is slowly improved, or perhaps a result of current treatment, as suggested by the persistence of inflammatory mediators (such as macrophages and T-cells) in lesions of patients on long term prostacyclin [33], a drug known to prolong survival but occasionally also suspected to induce inflammation $[34,35]$. In conclusion, we need to learn more about inflammation in $\mathrm{PAH}$, whether friend or foe, before calling the fire squads to the rescue.

\section{References}

1 Rather LJ. Disturbance of function (functio laesa): the legendary fifth cardinal sign of inflammation, added by Galen to the four cardinal signs of Celsus. Bull N Y Acad Med 1971; 47: 303-22.

2 Heidland A, Klassen A, Rutkowski P, et al. The contribution of Rudolf Virchow to the concept of inflammation: what is still of importance? J Nephrol 2006; 19: Suppl. 10, S102-S109.

3 Tuder RM, Groves B, Badesch DB, et al. Exuberant endothelial cell growth and elements of inflammation are present in plexiform lesions of pulmonary hypertension. Am J Pathol 1994; 144: 275-85.

4 Fartoukh M, Emilie D, Le Gall C, et al. Chemokine macrophage inflammatory protein-lalpha mRNA expression in lung biopsy specimens of primary pulmonary hypertension. Chest 1998; 114: 50S-51S.

5 Humbert M, Monti G, Brenot F, et al. Increased interleukin-1 and interleukin-6 serum concentrations in severe primary pulmonary hypertension. Am J Respir Crit Care Med 1995; 151: 1628-1631.

6 Sakamaki F, Kyotani S, Nagaya N, et al. Increased plasma P-selectin and decreased thrombomodulin in pulmonary arterial hypertension were improved by continuous prostacyclin therapy. Circulation 2000; 102: 2720-2725.

7 Wright L, Tuder RM, Wang J, et al. 5-Lipoxygenase and 5-lipoxygenase activating protein (FLAP) immunoreactivity in lungs from patients with primary pulmonary hypertension. Am J Respir Crit Care Med 1998; 157: 219-229.

8 Voelkel NF, Tuder RM, Wade K, et al. Inhibition of 5-lipoxygenase-activating protein (FLAP) reduces pulmonary vascular reactivity and pulmonary hypertension in hypoxic rats. J Clin Invest 1996; 97: 2491-2498.

9 Isern RA, Yaneva M, Weiner E, et al. Autoantibodies in patients with primary pulmonary hypertension: association with anti-Ku. Am J Med 1992; 93: 307-312.

10 Tamby MC, Chanseaud Y, Humbert M, et al. Anti-endothelial cell antibodies in idiopathic and systemic sclerosis associated pulmonary arterial hypertension. Thorax 2005; 60: 765-772.

11 Nicolls MR, Taraseviciene-Stewart L, Rai PR, et al. Autoimmunity and pulmonary hypertension: a perspective. Eur Respir J 2005; 26: 1110-1118.

12 Tamby MC, Humbert M, Guilpain P, et al. Antibodies to fibroblasts in idiopathic and scleroderma-associated pulmonary hypertension. Eur Respir J 2006; 28: 799-807.

13 Le Pavec J, Humbert M, Mouthon L, et al. Systemic sclerosis-associated pulmonary arterial hypertension. Am J Respir Crit Care Med 2010; 181: 1285-1293.

14 Hassoun PM, Mouthon L, Barbera JA, et al. Inflammation, growth factors, and pulmonary vascular remodeling. J Am Coll Cardiol 2009; 54: S10-S19.

15 Voelkel NF, Gomez-Arroyo J, Abbate A, et al. Pathobiology of pulmonary arterial hypertension and right ventricular failure. Eur Respir J 2012; 40: 1555-1565.

16 Cracowski JL, Leuchte HH. The potential of biomarkers in pulmonary arterial hypertension. Am J Cardiol 2012; 110: 32S-38S.

17 El Chami H, Hassoun PM. Immune and inflammatory mechanisms in pulmonary arterial hypertension. Prog Cardiovasc Dis 2012; 55: 218-228.

18 Huertas A, Tu L, Gambaryan N, et al. Leptin and regulatory T-lymphocytes in idiopathic pulmonary arterial hypertension. Eur Respir J 2012; 40: 895-904.

19 Malhotra R, Paskin-Flerlage S, Zamanian RT, et al. Circulating angiogenic modulatory factors predict survival and functional class in pulmonary arterial hypertension. Pulm Circ 2013; 3: 369-380.

20 Soon E, Holmes AM, Treacy CM, et al. Elevated levels of inflammatory cytokines predict survival in idiopathic and familial pulmonary arterial hypertension. Circulation 2010; 122: 920-927.

21 Cracowski J-L, Chabot F, Labarère J, et al. Proinflammatory cytokine levels are linked to death in pulmonary arterial hypertension. Eur Respir J 2014; 43: 915-917.

22 Miller DP, Gomberg-Maitland M, Humbert M. Survivor bias and risk assessment. Eur Respir J 2012; 40: 530-532.

23 Graham BB, Chabon J, Kumar R, et al. Protective role of IL-6 in vascular remodeling in schistosoma pulmonary hypertension. Am J Respir Cell Mol Biol 2013; 49: 951-959.

24 Steiner MK, Syrkina OL, Kolliputi N, et al. Interleukin-6 overexpression induces pulmonary hypertension. Circ Res 2009; 104: 236-244. 
Heresi GA, Aytekin M, Hammel JP, et al. Plasma interleukin-6 adds prognostic information in pulmonary arterial hypertension. Eur Respir J 2014; 43: 912-914.

26 Perros F, Dorfmuller P, Montani D, et al. Pulmonary lymphoid neogenesis in idiopathic pulmonary arterial hypertension. Am J Respir Crit Care Med 2012; 185: 311-321.

27 Stacher E, Graham BB, Hunt JM, et al. Modern age pathology of pulmonary arterial hypertension. Am J Respir Crit Care Med 2012; 186: 261-272.

28 Jais X, Launay D, Yaici A, et al. Immunosuppressive therapy in lupus- and mixed connective tissue diseaseassociated pulmonary arterial hypertension: a retrospective analysis of twenty-three cases. Arthritis Rheum 2008; 58 : 521-531.

29 Nicolls M, Badesch DB, Medsger TA. A Randomized, Double-Blind, Placebo-Controlled, Phase II Multicenter Trial of a Monoclonal Antibody to CD20 (Rituximab) for the Treatment of Systemic Sclerosis-associated Pulmonary Arterial Hypertension (SSc-PAH). http://clinicaltrials.gov/show/NCT01086540 Date last updated: August 17, 2013. Date last accessed: January 6, 2014.

30 Humbert M. Impression, sunset. Circulation 2013; 127: 1098-1100.

31 Wagenvoort CA. The pathology of primary pulmonary hypertension. J Pathol 1970; 101: Pi.

32 Pietra GG, Edwards WD, Kay JM, et al. Histopathology of primary pulmonary hypertension. A qualitative and quantitative study of pulmonary blood vessels from 58 patients in the National Heart, Lung, and Blood Institute, Primary Pulmonary Hypertension Registry. Circulation 1989; 80: 1198-1206.

33 Pogoriler JE, Rich S, Archer SL, et al. Persistence of complex vascular lesions despite prolonged prostacyclin therapy of pulmonary arterial hypertension. Histopathology 2012; 61: 597-609.

34 Kesten S, Dainauskas J, McLaughlin V, et al. Development of nonspecific interstitial pneumonitis associated with long-term treatment of primary pulmonary hypertension with prostacyclin. Chest 1999; 116: 566-569.

35 Kudelko KT, Nadeau K, Leung AN, et al. Epoprostenol-associated pneumonitis: diagnostic use of a T-cell proliferation assay. J Heart Lung Transplant 2010; 29: 1071-1075. 